Corrigendum

\title{
Corrigendum to "Mesoscale and Local Scale Evaluations of Quantitative Precipitation Estimates by Weather Radar Products during a Heavy Rainfall Event"
}

\author{
Basile Pauthier, ${ }^{1}$ Benjamin Bois, ${ }^{1}$ Thierry Castel, ${ }^{1}$ D. Thévenin, ${ }^{2}$ \\ Carmela Chateau Smith, ${ }^{3}$ and Yves Richard ${ }^{1}$ \\ ${ }^{1}$ Centre de Recherche de Climatologie, Biogéosciences UMR 6282 CNRS, Université Bourgogne Franche-Comté, \\ 6 bd Gabriel, 21000 Dijon, France \\ ${ }^{2}$ Météo-France Direction Régionale Centre-Est, 22 rue Louis de Broglie, 21000 Dijon, France \\ ${ }^{3}$ UFR SVTE, Université Bourgogne Franche-Comté, 6 bd Gabriel, 21000 Dijon, France
}

Correspondence should be addressed to Basile Pauthier; basile.pauthier@civc.fr

Received 7 March 2017; Accepted 19 March 2017; Published 10 May 2017

Copyright (c) 2017 Basile Pauthier et al. This is an open access article distributed under the Creative Commons Attribution License, which permits unrestricted use, distribution, and reproduction in any medium, provided the original work is properly cited.

In the article titled "Mesoscale and Local Scale Evaluations of Quantitative Precipitation Estimates by Weather Radar Products during a Heavy Rainfall Event" [1], the email address of the corresponding author should be changed to "basile.pauthier@civc.fr."

\section{References}

[1] B. Pauthier, B. Bois, T. Castel, D. Thévenin, C. C. Smith, and Y. Richard, "Mesoscale and local scale evaluations of quantitative precipitation estimates by weather radar products during a heavy rainfall event," Advances in Meteorology, vol. 2016, Article ID 6089319, 9 pages, 2016. 

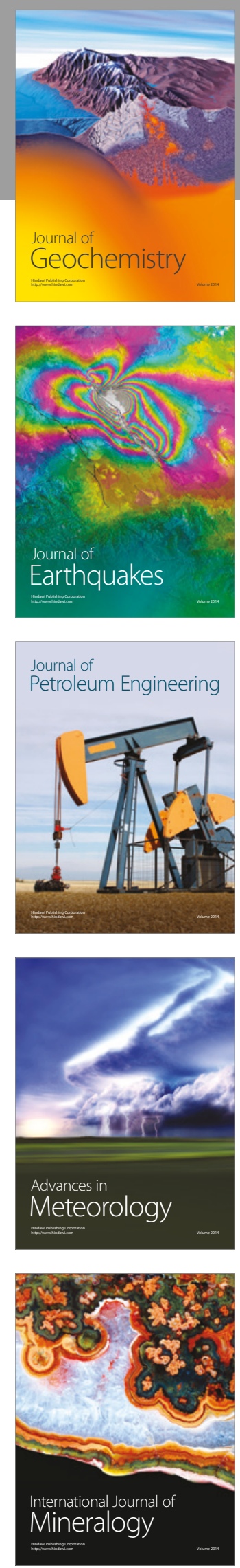
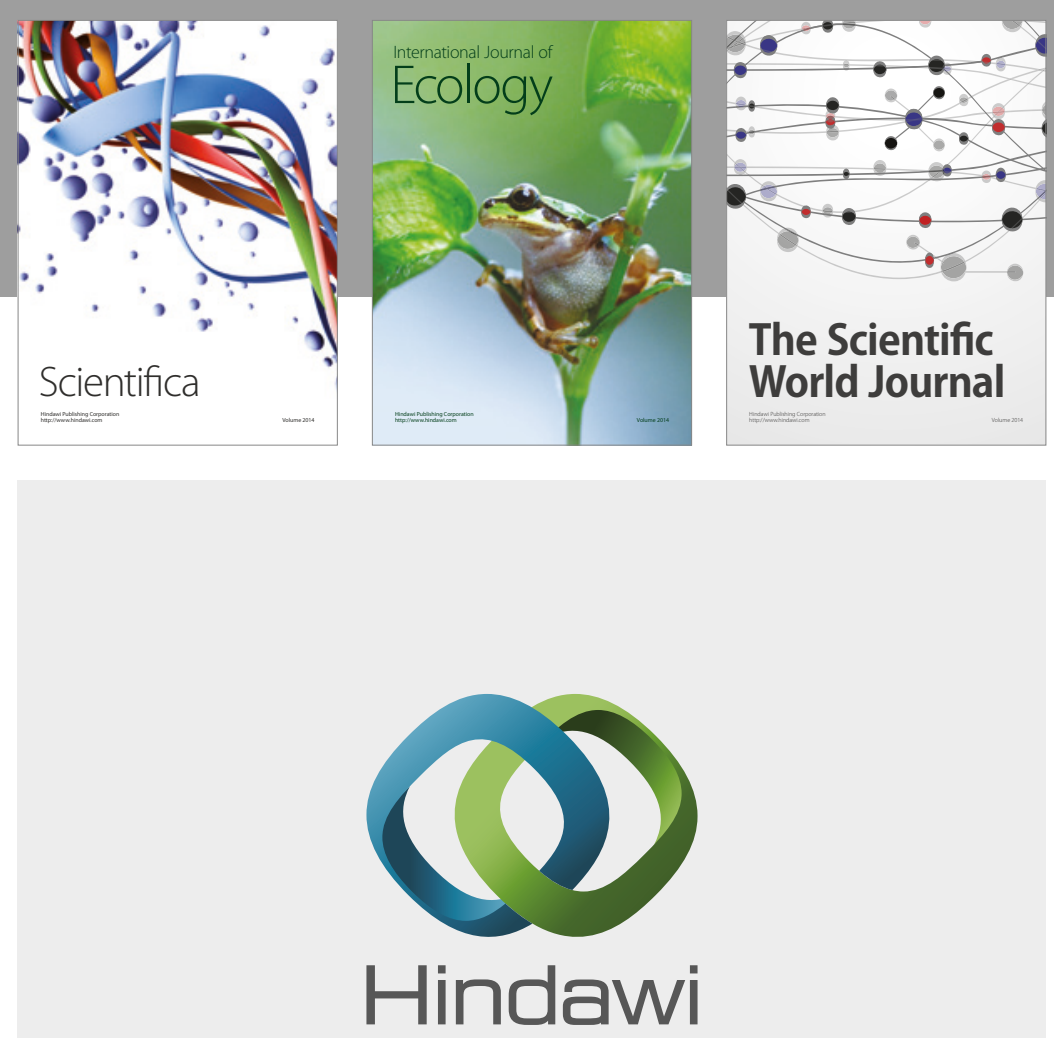

Submit your manuscripts at

https://www.hindawi.com
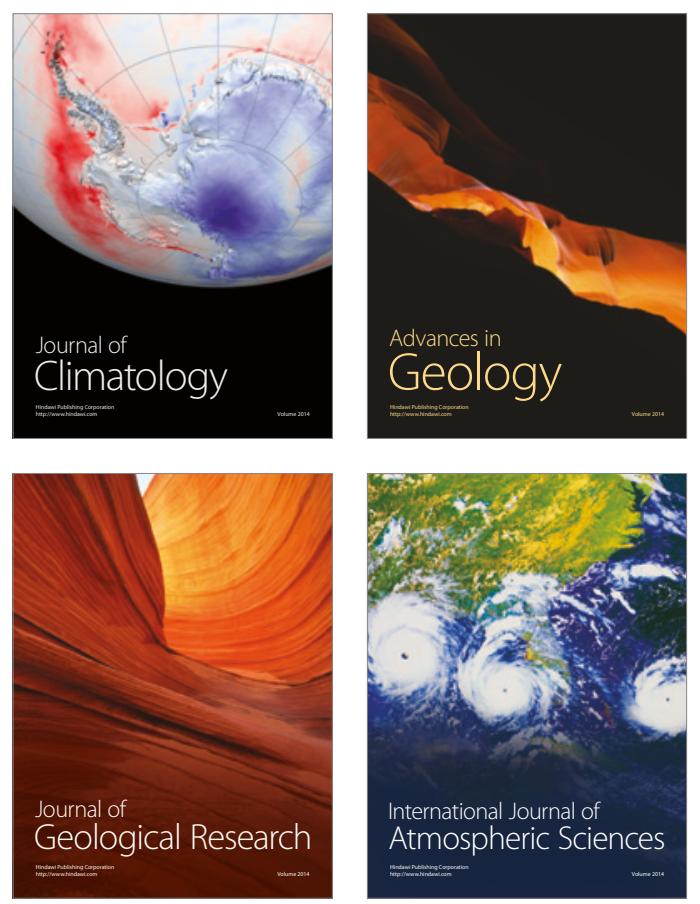

The Scientific

World Journal
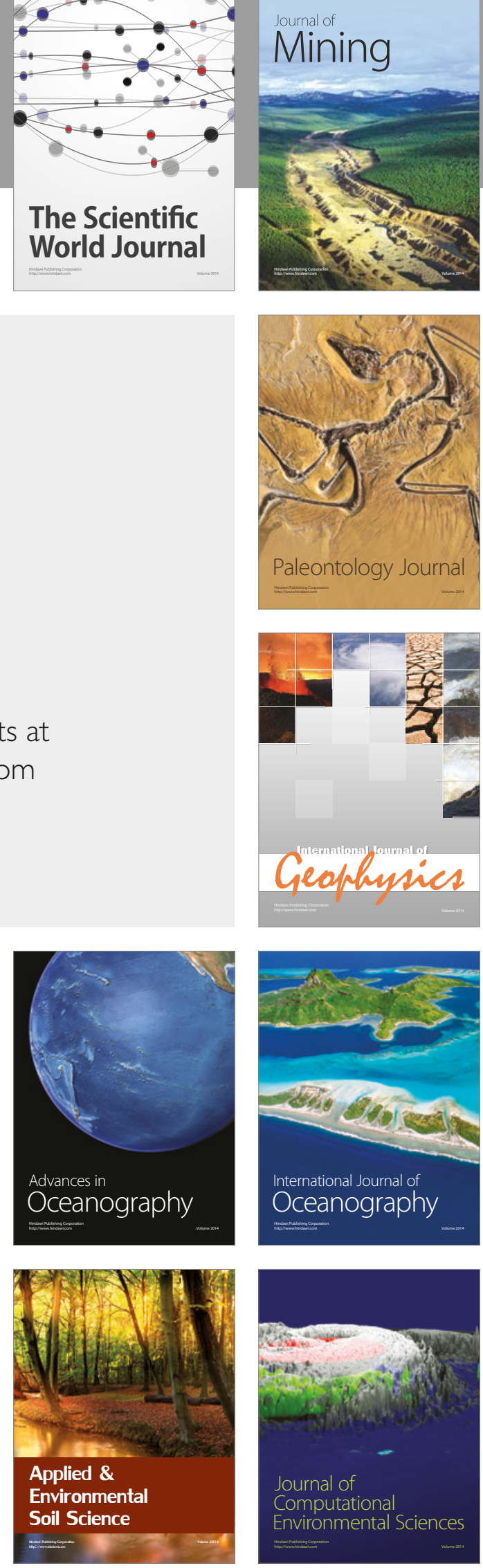